\title{
Structure of Overfire Soot in Buoyant Turbulent Diffusion Flames at Long Residence Times
}

\author{
Ü. Ö. KÖYL ̈̈̈ and G. M. FAETH* \\ Department of Aerospace Engineering, The University of Michigan, Ann Arbor, MI 48109-2140
}

\begin{abstract}
The structure of soot was investigated within the fuel-lean (overfire) region of overventilated buoyant turbulent diffusion flames burning in still air. The study was limited to the long residence time regime where characteristic flame residence times are roughly more than an order of magnitude longer than the laminar smoke point residence time and soot generation factors (the mass of soot emitted per unit mass of fuel carbon burned) are relatively independent of flame residence times. Both gaseous and liquid fuels were used to provide a range of $\mathrm{H} / \mathrm{C}$ ratios (1-2.7) and fuel types (alkynes, alkenes, alkanes, aromatics, and alcohols) as follows: toluene, acetylene, benzene, propylene, ethylene, $n$-heptane, propane, and isopropanol. Measurements included transmission electron microscopy to find primary particle diameters, the number of primary particles per aggregate and aggregate geometrical and fractal dimensions. The results show that the structure of soot varies with fuel type but is relatively independent of both position in the overfire region and flame residence time for the long residence time regime. Mean primary particle diameters were $30-51 \mathrm{~nm}$ and the mean number of primary particles per aggregate were 255-552, with the larger values associated with the more heavily sooting fuels. Aggregate fractal dimensions, however, were less dependent on fuel type, only varying in the range 1.70-1.79. The structure measurements are used to estimate the optical properties of overfire soot, based on a recent approximate theory for polydisperse aggregates, finding significant differences between aggregate and Rayleigh scattering properties in the visible and near-infrared portions of the spectrum, even though the primary particles are well within the Rayleigh scattering regime.
\end{abstract}

\section{NOMENCLATURE}

$A_{A}$

$A_{p}$

projected area of aggregate

mean crossectional area of primary particles

d burner diameter

$d_{p}$

$d_{p g}$

$D_{f}$

$D_{30}$

$D_{60}$

primary particle diameter

geometric mean primary particle

diameter

aggregate fractal or Hausdorff dimension

volume mean diameter of aggregates

sixth moment of volume equivalent diameter

$E(m)$ refractive index function, Eq. 19

$f$ mixture fraction

$f_{n} \quad$ moment ratio, $\bar{N}^{2} /(\bar{N})^{2}$

$f_{V A} \quad$ soot volume fraction estimate from aggregate theory

$f_{V R} \quad$ soot volume fraction estimate from Rayleigh theory

$F(m) \quad$ refractive index function, Eq. 19 g

$H$

$k_{f}$
$K$

$L$

$m$

$M_{C}$

$M_{F}$

$n_{A}$

$n_{i}$

$n_{p}$

$n_{t}$

$N$

$N_{g}$

$\operatorname{pdf}(\phi)$

$\dot{Q}_{f}$

$\operatorname{Re}$

$R_{g}$

$\mathrm{Ri}$

$t_{r}$ acceleration of gravity

average flame height

prefactor constant, Eq. 7

agglomeration coefficient, Eq. 15

projected maximum length of aggregate

refractive index of soot

mass of carbon per $\mathrm{kg}$ mol of fuel

molecular weight of fuel

number of aggregates per unit volume

number of items having property $\phi_{i}$ in a sample

number of primary particles per unit volume

total number of items in sample

number of primary particles in an aggregate

geometric mean of number of primary particles per aggregate

probability density function of $\phi$ heat release rate of flame

burner Reynolds number, $u_{0} d / \nu_{0}$

radius of gyration of an aggregate

burner Richardson number, $g d / u_{0}^{2}$

characteristic flame residence time

Copyright (C) 1992 by The Combustion Institute Published by Elsevier Science Publishing Co., Inc. 
$t_{s} \quad$ laminar smoke point residence time

$u \quad$ streamwise velocity

$W \quad$ maximum projected aggregate width perpendicular to $L$

$x$

height above burner

\section{Greek Symbols}

$\alpha \quad$ projected area exponent

$\alpha_{p} \pi d_{p} / \lambda$

$\eta_{A} \quad$ aggregate generation factor

$\eta_{p} \quad$ primary particle generation factor

$\eta_{s} \quad$ soot generation factor

$\rho$ density

$\rho_{s} \quad$ soot density

$\bar{\rho}_{s a}$ mean ratio of scattering to absorption crossection of polydisperse aggregates

$\nu \quad$ kinematic viscosity

$\sigma_{A}$ standard deviation of mean number of primary particles per aggregate

$\sigma_{p} \quad$ standard deviation of mean primary particle diameter

$\sigma_{p g}$ geometric standard deviation of primary particle diameter

$\sigma_{A g}$ geometric standard deviation of number of primary particles per aggregate

$\phi \quad$ generic property

$\phi_{g}$ geometric mean value of $\phi$

\section{Superscripts}

$(\bar{\phi})$ arithmetic mean value of $\phi$

\section{INTRODUCTION}

The present investigation considers the structure of soot within the fuel-lean (overfire) region of overventilated buoyant turbulent diffusion flames burning in still air. The study was motivated by the influence of the structure of soot on continuum radiation and carbon monoxide emissions from flames [1-3]-two major hazards of unwanted fires. Thus, measurements were made of the structure of overfire soot to obtain a better understanding of the radiative (optical) and reactive properties of soot in turbulent diffusion flames. Additionally, the structure measurements were used to estimate the optical properties of overfire soot, based on a recent approximate theoryfor soot aggregates [4, 5].
Present measurements were limited to poollike fires in the long residence time regime, where soot and carbon monoxide generation factors (the mass of soot or carbon monoxide emitted from the flame per unit mass of fuel carbon burned) are relatively independent of both position in the overfire region and flame residence time for a particular fuel [1-3]. This regime involves characteristic flame residence times roughly more than an order of magnitude longer than the laminar smoke point residence time of the fuel. These conditions are of interest because most unwanted fires are in the long residence time regime. Additionally, the invariance of soot generation factors at long residence times suggests that the physical properties of soot might be invariant in this regime as well-a possibility that merits study because it implies useful generalizations of soot properties in the overfire region of practical turbulent flames.

Earlier studies of the structure of soot in nonpremixed flames largely have been confined to laminar flames, see Refs. 6-10 and references therein. In general, soot has been collected using either sampling or thermophoretic probes and examined using transmission electron microscopy (TEM). Soot consists of small individual (primary) particles near the point of soot inception; however, these particles agglomerate rapidly so that aggregates consisting of nearly spherical and monodisperse primary particles dominate soot morphology in nonpremixed flames [7-9]. In regions where observations were made, primary particle diameters vary in the range $10-50 \mathrm{~nm}$ with aggregates consisting of a wide range of primary particles, $10-10^{4}$ - both generally satisfying log-normal probability density functions $[6,10]$. Although the structure of soot aggregates is complex, recent work has shown that they can be characterized as mass fractal-like materials, providing useful relationships between their size and the number of primary particles they contain, see Refs. 11 and 12 and references therein. Thus, contemporary work on soot structure in nonpremixed flames generally includes measurements of the fractal properties of aggregates [6-9]. Soot aggregates were also observed in the overfire region of the present turbulent flames, prompting similar characterization of their properties.

Early studies of the optical properties of soot suggested that soot aggregates satisfied the small-particle (Rayleigh) scattering limit, which 
vastly simplifies both the interpretation of extinction measurements to find soot concentrations and estimates of continuum radiation properties of soot in flames [12]. Recent measurements of the structure of soot aggregates, however, raise questions about the effectiveness of the Rayleigh scattering approximation for wavelengths of interest for concentration measurements and continuum radiation predictions. This has lead to detailed computations of the optical properties of simulated soot aggregates, assuming that the primary particles satisfy the Rayleigh scattering condition [13-19]. The optical properties of aggregates depend on their size and arrangement; however, Dobbins and coworkers [4,5] have been able to generalize these results using a porous-sphere approximation in conjunction with the statistical and mass fractal properties of the aggregates. These results suggest that scattering from large aggregates is larger than estimates based on the Rayleigh scattering approximation that applies to the primary particles and small aggregates. Thus, information on aggregate structure in the long residence time regime of buoyant turbulent flames is needed to determine the effect of aggregate scattering on optical measurements of soot concentrations, like those of Refs. 1-3, as well as on continuum radiation properties.

The previous discussion indicates that little is known about the structure of soot in the fuel-lean (overfire) region of buoyant turbulent diffusion flames. Thus, the objectives of the present investigation were to use TEM to find soot structure, for example, primary particle diameters, number of primary particles per aggregate and aggregate geometrical and fractal dimensions. Measurements were limited to the overfire region of buoyant turbulent diffusion flames in the long residence time regime because these conditions have the potential for universal behavior of soot properties that would simplify consideration of practical turbulent flames. Thus, particular emphasis was placed on the variation of soot structure with respect to position in the overfire region and flame residence time. Both gaseous and liquid fuels were studied to provide a wide range of fuel $\mathrm{H} / \mathrm{C}$ ratios $(1-2.7)$ and fuel types (alkynes, alkenes, alkanes, aromatics, and alcohols). Specific fuels considered, listed in the order of decreasing tendency to soot, were as follows: toluene, acetylene, benzene, propylene, ethylene, $n$-heptane, propane, and isopropanol.
These fuels were the same as those studied during earlier work on soot emissions in this laboratory [1-3].

The article begins with discussion of experimental methods. Results are then described, considering soot structure, aggregation, and aggregate optical properties, in turn.

\section{EXPERIMENTAL METHODS}

\section{Apparatus}

The overall test arrangement was identical to earlier experiments in this laboratory for gas $[1,2]$ and liquid [3] fueled turbulent diffusion flames. Combustion was in still air with the burners located near the axis of a large enclosure $(2.4 \times 2.4 \times 3.6 \mathrm{~m}$ high $)$. The enclosure had a metal hood at the top and an adjustable exhaust system to collect and remove combustion products without disturbing the flames. Room disturbances of the flames were minimized by using strips of plastic film, terminating near the floor, as the side walls of the enclosure with a second screened enclosure $(1 \times 1 \times 2 \mathrm{~m}$ high, open at the top) directly around the flames. Instrumentation was mounted rigidly so that the burners were traversed horizontally and vertically (with positioning accuracies of 0.1 and $1 \mathrm{~mm}$, respectively) to make measurements at various positions within the fuel-lean (overfire) region of the flames.

The gas-fueled burner was the same as in Refs. 1 and 2. This involved a water-cooled burner directed vertically upward with an exit diameter of $50 \mathrm{~mm}$. The flames attached naturally at the burner exit. The liquid-fueled burners consisted of horizontal round fuel-saturated wicks (Carborundum Co., Duraboard KBLD162436, $25 \mathrm{~mm}$ thick) having diameters of 50,125 , and $195 \mathrm{~mm}$. The wicks were mounted level with the top of close-fitting stainless-steel pans so that burning from the sides of the wicks was inhibited. The wicks were mounted on a load cell so that burning rates could be matched to conditions considered earlier [3].

\section{Instrumentation}

The structure of soot was measured by thermophoretic sampling and analysis using TEM, similar to Dobbins and Megaridis [7-9]. The 
sampling surfaces were the carbon-supported copper grids used to hold TEM specimens (3-mm-diameter 200 mesh copper grids supported by a 200 - $\AA$-thick elemental carbon film, SPI Supplies, Philadelphia, part no. 3520C), aligned in the vertical direction, roughly parallel to the mean flow direction. The grids were attached to glass microscope slides with double backed adhesive. and the slides were mounted in turn to a retractable probe. The probe was stored in a cylinder, having a spring-loaded door at the end, positioned outside the plume above the fire. A double-acting pneumatic cylinder rapidly drove the probe out of the cylinder to the sampling position and returned it again to the cylinder when sampling was complete. Sampling times were measured using a translation potentiometer with output recorded on a digital oscilloscope. Sampling times were selected so that soot aggregates covered no more than $10 \%$ of the surface of the TEM grid to avoid overlapping aggregates on the grid. This involved relatively long sampling times, on the order of seconds, in comparison with Refs. 7-9, because plume temperatures were relatively low (less than $450 \mathrm{~K}$ ) in the region when samples were obtained that reduced thermophoretic velocities in comparison with flame environments. Care was taken to ensure that grids were not contaminated by using a new microscope slide with each new grid, cleaning the probe storage assembly and microscope slide with alcohol, and maintaining a small purge flow of clean air through the probe storage cylinder.

The principles of thermophoretic sampling are discussed elsewhere $[7-9,20,21]$. For the present test conditions, because the primary particle sizes (less than $60 \mathrm{~nm}$ ) are smaller than the mean free path, there is no variation in thermophoretic velocities of individual particles. The issue of preferential collection is less clear for aggregates, particularly large aggregates that can have maximum dimensions of several microns. If the aggregates are assumed to be solid spheres, the variation of thermophoretic velocities over the size range of $95 \%$ of the aggregates (as discussed later, 30-1800 primary particles per aggregate yielding equivalent sphere diameters in the range $150-600 \mathrm{~nm}$ ) is less than $20 \%$ [21]. This estimate probably is conservative, however, because the present aggregates were open structures of primary particles with fractal dimensions in the range $1.70-1.79$, which are likely to have negligible internal temperature gradients, characteristic of the primary particles themselves. Nevertheless, more information about the thermophoretic velocities of soot aggregates is needed to definitely evaluate effects of sampling bias on the thermophoretic sampling technique.

The samples were observed using a JEOL 2000 FX analytical electron microscope system with a 1-nm edge-to-edge resolution and sample tilting angles up to $\pm 45^{\circ}$. Magnifications used for present measurements were in the range 600-200,000. The procedure involved selecting aggregates randomly at low magnification, and then increasing the magnification to analyze them. Aggregate images could be saved using a camera-Macintosh II system or after digitization on a computer hard disk. Images were processed using the IMAGE computer algorithm to find primary particle diameters and aggregate areas and dimensions. Latex spheres having a diameter of $91 \mathrm{~nm}$ (with a standard deviation of $5.8 \mathrm{~nm}$ ) were used to calibrate the TEM images. Experimental uncertainties of soot structure parameters derived from these measurements are considered when the results are discussed. All measurements were repeatable within the stated experimental uncertainties.

\section{Test Conditions}

Test conditions are summarized in Table 1 . Richardson numbers of the tests are based on burner exit conditions, finding flow velocities from the measured burning rate. The density of the fuel at the burner exit was found assuming that burner exit temperatures were equal to ambient temperatures for the gaseous fuels or equal to the fuel vapor density at the normal boiling point for the liquid fuels. Richardson numbers generally are in excess of 7 , which is representative of strongly buoyant flames. All the flames were turbulent except for a thin region near the base of the poollike fires. Test conditions were limited to the long residence time regime identified in Refs. 1-3. This involved flame residence times more than an order of magnitude longer than the smoke point residence time of the fuel. For present purposes, flame residence time was taken as the time between the termination of fuel flow at the burner exit, with a shutter, and the disappearance of all flame luminosity; the technique used to find residence times and residence time corre- 
TABLE 1

Summary of Test Conditions ${ }^{\mathrm{a}}$

\begin{tabular}{|c|c|c|c|c|c|c|}
\hline$\underset{(\mathrm{mm})}{d}$ & $\mathbf{R i}^{b}$ & $\operatorname{Re}^{c}$ & $\underset{(\mathrm{kW})}{\dot{Q}_{f}}$ & $\begin{array}{c}H \\
(\mathrm{~mm})\end{array}$ & $\begin{array}{c}t_{r}^{d} \\
(\mathrm{~ms})\end{array}$ & $x / d^{e}$ \\
\hline \multicolumn{7}{|c|}{ Toluene (liquid, $\rho_{0}=3.11 \mathrm{~kg} / \mathrm{m}^{3}, t_{s}=13 \mathrm{~ms}$ ) $f$} \\
\hline 50 & 6270 & - & 2.3 & 295 & 279 & 19.0 \\
\hline 125 & 15450 & - & 14.4 & 520 & 531 & 11.5 \\
\hline \multicolumn{7}{|c|}{ Acetylene (gas, $\rho_{0}=1.08 \mathrm{~kg} / \mathrm{m}^{3}, t_{s}=14 \mathrm{~ms}$ ) } \\
\hline 50 & $20-1245$ & $105-840$ & $2.3-18.0$ & $300-550$ & $132-295$ & $28.5-37.5$ \\
\hline \multicolumn{7}{|c|}{ Benzene (liquid, $\rho_{0}=2.69 \mathrm{~kg} / \mathrm{m}^{3}, t_{\mathrm{s}}=15 \mathrm{~ms}$ ) } \\
\hline 50 & 3150 & - & 2.7 & 280 & 273 & 19.0 \\
\hline 125 & 10930 & - & 14.1 & 525 & 510 & 13.0 \\
\hline \multicolumn{7}{|c|}{ Propylene (gas, $\rho_{0}=1.70 \mathrm{~kg} / \mathrm{m}^{3}, t_{s}=16 \mathrm{~ms}$ ) } \\
\hline 50 & $24-258$ & $430-1370$ & $6.6-21.1$ & $450-718$ & $474-600$ & $24.5-37.5$ \\
\hline \multicolumn{7}{|c|}{ Ethylene (gas, $\rho_{0}=1.16 \mathrm{~kg} / \mathrm{m}^{3}, t_{s}=41 \mathrm{~ms}$ ) } \\
\hline 50 & $7-207$ & $280-1520$ & $4.5-24.5$ & $475-775$ & $304-338$ & $28.5-37.5$ \\
\hline \multicolumn{7}{|c|}{$n$-Heptane (liquid, $\rho_{0}=3.29 \mathrm{~kg} / \mathrm{m}^{3}, t_{s}=41 \mathrm{~ms}$ ) } \\
\hline 125 & 58230 & - & 8.2 & 450 & 412 & 6.5 \\
\hline 195 & 87010 & - & 20.5 & 650 & 532 & 7.4 \\
\hline \multicolumn{7}{|c|}{ Propane (gas, $\rho_{0}=1.77 \mathrm{~kg} / \mathrm{m}^{3}, t_{s}=48 \mathrm{~ms}$ ) } \\
\hline 50 & $99-290$ & $450-770$ & $7.6-13.0$ & $493-550$ & $437-552$ & $24.5-33.0$ \\
\hline \multicolumn{7}{|c|}{ Isopropanol (liquid, $\rho_{0}=2.06 \mathrm{~kg} / \mathrm{m}^{3}, t_{s}=49 \mathrm{~ms}$ ) } \\
\hline 125 & 30610 & - & 5.3 & 370 & 324 & 5.6 \\
\hline 195 & 47600 & - & 12.9 & 510 & 495 & 7.4 \\
\hline
\end{tabular}

\footnotetext{
${ }^{a}$ Vertical fuel injection for gas fuels and vaporization from a horizontal wick for liquid fuels; combustion in still air at normal temperature and pressure.

${ }^{b} \mathrm{Ri}=g d / u_{0}^{2}$ based on average velocity at burner exit conditions.

${ }^{c} \operatorname{Re}=u_{0} d / \nu_{0}$ based on average velocity at burner exit conditions.

${ }^{d}$ Time between termination of fuel flow and disappearance of all flame luminousity.

${ }^{e}$ Measurements along burner axis for this range or value of $x / d$.

$f_{t_{s}}$ is time between termination of fuel flow and disappearance of all flame luminousity at the laminar smoke point.
}

lations for poollike fires is discussed elsewhere $[1,3]$.

\section{RESULTS AND DISCUSSION}

\section{Soot Structure}

\section{Aggregate Appearance}

The general appearance of the soot aggregates was similar for all positions, residence times, and fuels, and the aggregates were also qualitatively similar to earlier observations for laminar flames [6-12]. A TEM photograph of acetylene soot in the long residence-time regime appears in Fig. 1. The soot consists of wispy open structures of aggregated primary particles. The aggregates involve nearly constant primary particle diameters with a large variation in the number of primary particles per aggregate, for example, dimensions of aggregates varied in the range $0.1-10 \mu \mathrm{m}$. This behavior has prompted approximation of aggregates as collections of monodisperse primary particles, with more detailed consideration of the statistics of aggregate size, during past studies of aggregate optical properties [4, 5, 13-18].

Measurements of aggregate properties were undertaken over the full range of operating conditions summarized in Table 1 . However, it soon became evident that aggregate properties only varied with the fuel: within experimental uncertainties, there were no significant variations with 


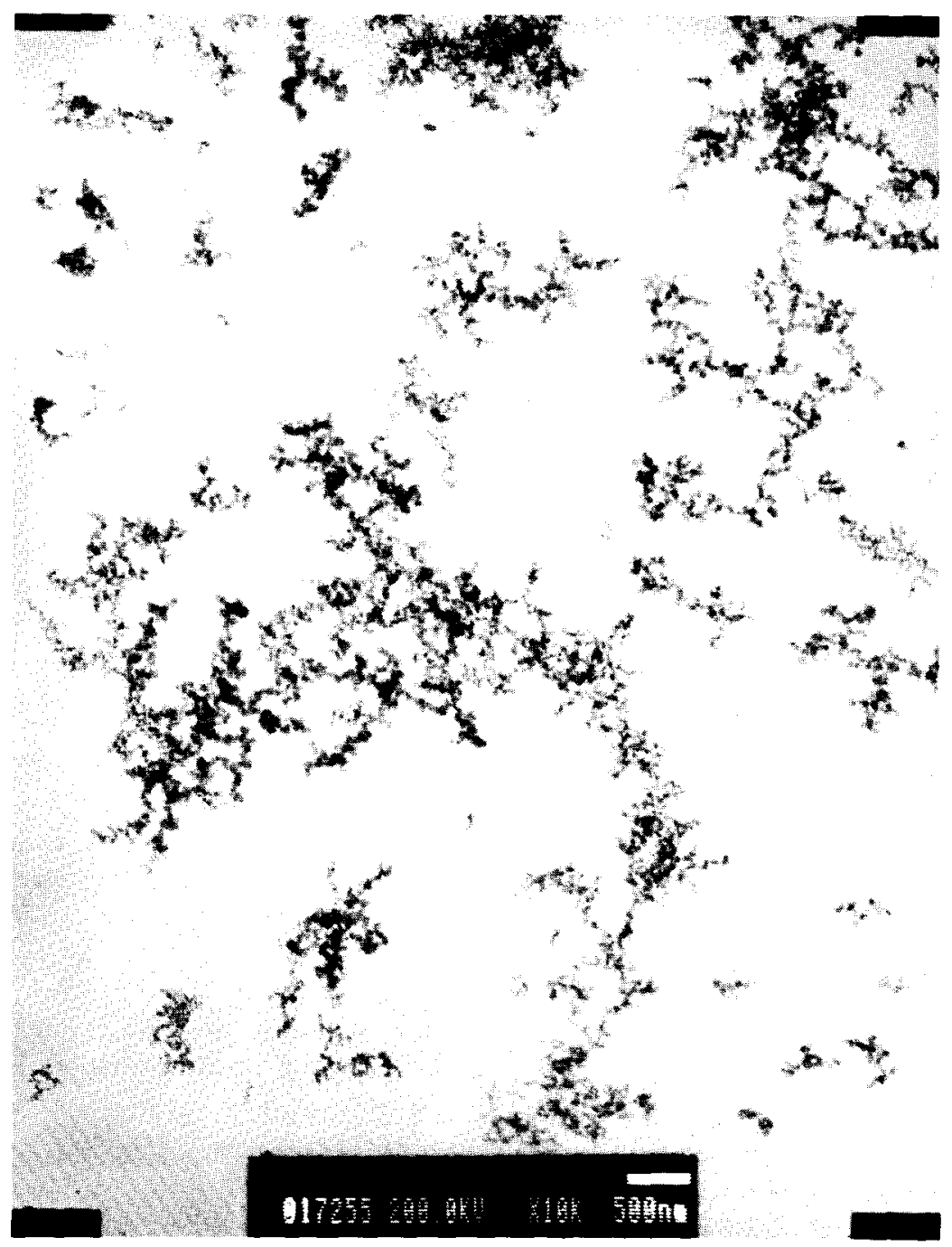

Fig. 1. Typical TEM photograph of soot aggregates in the overfire region of turbulent acetylene/air diffusion flames at long residence times

position in the overfire region or flame residence time within the long residence time regime. Thus, soot structure behaves like soot generation factor in the long residence time regime, simplifying structure characterization to a single statistical population for a particular fuel. As a result, aggregate properties frequently will be denoted only by the fuel in the following, in order to reduce cluttering of tables and figures. The likelihood of variations of aggregate properties over a wider range of conditions than the present tests is taken up later.

\section{Primary Particle Properties}

Primary particle diameters were determined from linear measurements at high magnification. Statis- tically significant information on the probability density functions (pdf) of primary particle diameters was obtained by measuring 550-1500 primary particles within 160-320 aggregates for each fuel to obtain uncertainties ( $95 \%$ confidence) of $\bar{d}_{p}$ less than $2 \%$. It was found that a log-normal pdf provided a reasonably good fit of the measurements. The log-normal distribution of a generic property, $\phi$, is defined as follows [21]:

$$
\begin{aligned}
\operatorname{pdf}(\phi, & \left.\phi_{g}, \sigma_{\phi g}\right) \\
= & \exp \left[-\left(\ln \left(\phi / \phi_{g}\right) / \ln \sigma_{\phi g}\right)^{2} / 2\right] / \\
& \times\left[(2 \pi)^{1 / 2} \phi \ln \sigma_{\phi g}\right]
\end{aligned}
$$


where $\phi_{g}$ and $\sigma_{\phi g}$ are geometric mean value and geometric standard deviation of $\phi$, defined as follows:

$\ln \phi_{g}=\left(\sum n_{i} \ln \phi_{i}\right) / n_{i}$,

$\ln \sigma_{\phi g}=\left(\sum n_{i}\left(\ln \left(\phi_{i} / \phi_{g}\right)\right)^{2} /\left(n_{t}-1\right)\right]^{1 / 2}$,

where $n_{i}$ is the number of samples having a value of $\phi_{i}$ while $n_{t}$ is the total number of samples.

Because $d_{p}$ cannot be negative, the log-normal distribution of Eq. 1 provides a better formal representation of the probability density function of $d_{p}$ than the normal distribution. However, the standard deviations of $d_{p}$ were small in comparison to the mean values so that a normal distribution provided a reasonable fit as well. Typical probability density functions of $d_{p}$, along with normal distributions, are illustrated in Fig. 2. Results are shown for both acetylene and ethylene soot, which are representative of heavily and lightly sooting fuels, at various positions in the overfire region and flame-operating conditions. The normal distribution is seen to provide a reasonably good fit of the data except for a slight bias of the measurements toward larger primary particles - the behavior of the other fuels was similar.

Results of the measurements of $d_{p}$ for all the fuels are summarized in the first two columns of Table 2. The fuels are listed in Table 2 in the order of decreasing tendency to soot, as measured by increasing laminar smoke point residence times (see Table 1). The entries in Table 2 include the mean and geometric mean values of $d_{p}$, as well as the corresponding standard deviations of each. The standard deviations of $d_{p}$ are relatively small,

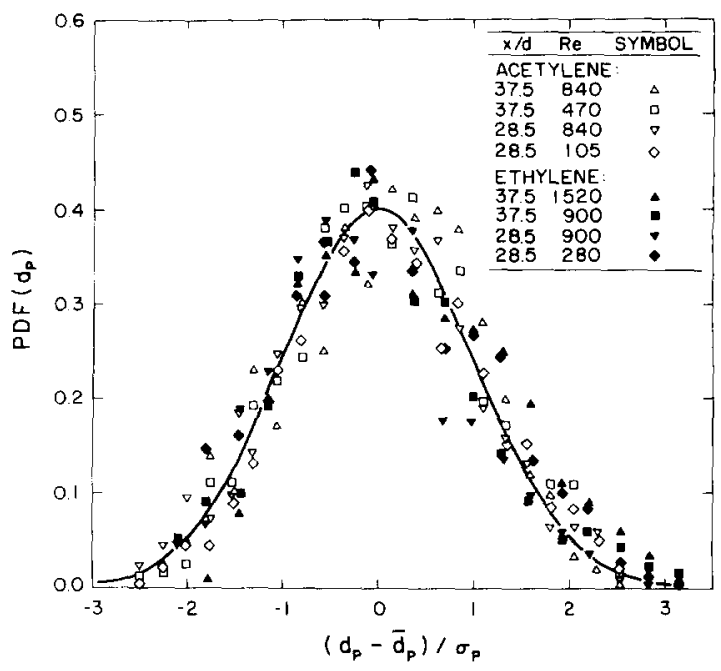

Fig. 2. Probability density functions of primary particle diameters for acetylene and ethylene soot.

corresponding to $17 \%-25 \%$ of $\bar{d}_{p}$ over all the fuels. This behavior supports the approximation of $\operatorname{pdf}\left(d_{p}\right)$ as a normal distribution, which is also suggested by the rather close correspondence between the arithmetic and geometric mean values of $d_{p}$. Another interesting feature of the results for $d_{p}$ in Table 2 is that $\bar{d}_{p}$ and $d_{p g}$ are ordered roughly in terms of fuel's propensity to soot. More general correlations of primary particle and aggregate properties in terms of fuel properties are taken up later.

\section{Aggregate Properties}

A major issue with respect to aggregate properties is whether the number of primary particles in an aggregate can be observed from a two-

TABLE 2

Soot Aggregate Properties at Long Residence Times ${ }^{a}$

\begin{tabular}{|c|c|c|c|c|c|c|c|c|c|}
\hline Fuel & $\begin{array}{c}\bar{d}_{p}\left(\sigma_{p}\right) \\
(\mathrm{nm})\end{array}$ & $\begin{array}{c}\bar{d}_{p g}\left(\sigma_{p g}\right) \\
(\mathrm{nm})\end{array}$ & $\bar{N}\left(\sigma_{A}\right)^{b}$ & $N_{g}\left(\sigma_{A g}\right)^{b}$ & $\begin{array}{c}D_{30} \\
(\mathrm{~nm})\end{array}$ & $f_{n}$ & $D_{f}$ & $\begin{array}{c}\bar{R}_{g}^{c} \\
(\mathrm{~nm})\end{array}$ & $\begin{array}{c}\left(\bar{R}_{g}^{2}\right)^{1 / 2^{c}} \\
(\mathrm{~nm})\end{array}$ \\
\hline Toluene & $51(9.2)$ & $50(1.2)$ & $526(903)$ & $252(3.2)$ & 411 & 3.23 & 1.73 & 626 & 807 \\
\hline Acetylene & $47(8.2)$ & $46(1.2)$ & $417(621)$ & $214(3.3)$ & 350 & 3.20 & 1.79 & 472 & 578 \\
\hline Benzene & $50(8.7)$ & $49(1.2)$ & $552(725)$ & $261(3.5)$ & 409 & 2.71 & 1.71 & 653 & 824 \\
\hline Propylene & $41(8.6)$ & $40(1.2)$ & $460(508)$ & $227(3.0)$ & 301 & 2.61 & 1.75 & 435 & 518 \\
\hline Ethylene & $32(6.4)$ & $31(1.2)$ & $467(557)$ & $290(2.7)$ & 247 & 2.42 & 1.73 & 387 & 452 \\
\hline$n$-Heptanc & $35(6.6)$ & $35(1.2)$ & $260(268)$ & $173(2.4)$ & 204 & 2.05 & 1.73 & 316 & 359 \\
\hline Propane & $30(6.3)$ & $29(1.2)$ & $364(455)$ & $224(2.7)$ & 214 & 2.56 & 1.74 & 313 & 366 \\
\hline Isopropanol & $31(7.6)$ & $30(1.3)$ & $255(324)$ & $166(2.5)$ & 196 & 2.61 & 1.70 & 284 & 330 \\
\hline
\end{tabular}

${ }^{a}$ For test conditions summarized in Table 1.

${ }^{b}$ Based on $\alpha=1.08$.

'Based on $k_{f}=5.8$. 
dimensional projected image. Several workers have found that the number of primary particles can be related to the projected area of soot aggregate, $A_{A}$, as follows [6-10]:

$N=\left(A_{A} / A_{p}\right)^{\alpha}$,

where $A_{p}=\pi \bar{d}_{p}^{2} / 4$ is the mean projected area of primary particles and $\alpha$ is an empirical projected-area exponent. The suitability of Eq. 4 for present test conditions was evaluated by observing stereopairs, which consist of micrograph pairs at two angles (about $10^{\circ}$ apart), of 12 acetylene aggregates containing from 5 to 505 primary particles. The resulting correlation between $N$ and $A_{A} / A_{p}$ is illustrated in Fig. 3. The correlation is seen to satisfy expectations of Eq. 4 quite well, with a least-squares fit of the data yielding $\alpha=1.08$ with an uncertainty ( $95 \%$ confidence) of 0.04 . This value is in good agreement with recent assessments of Eq. 4 (see Ref. 9 and references therein); therefore, the number of particles in the aggregates was found from Eq. 4 using measurements of projected areas and $\alpha=1.08$.

Computer images of 160-320 aggregates were used to find the probability density functions of the number of primary particles per aggregate to obtain uncertainties of $\bar{N}(95 \%$ confidence) less than $20 \%$, except for toluene, where the uncer-

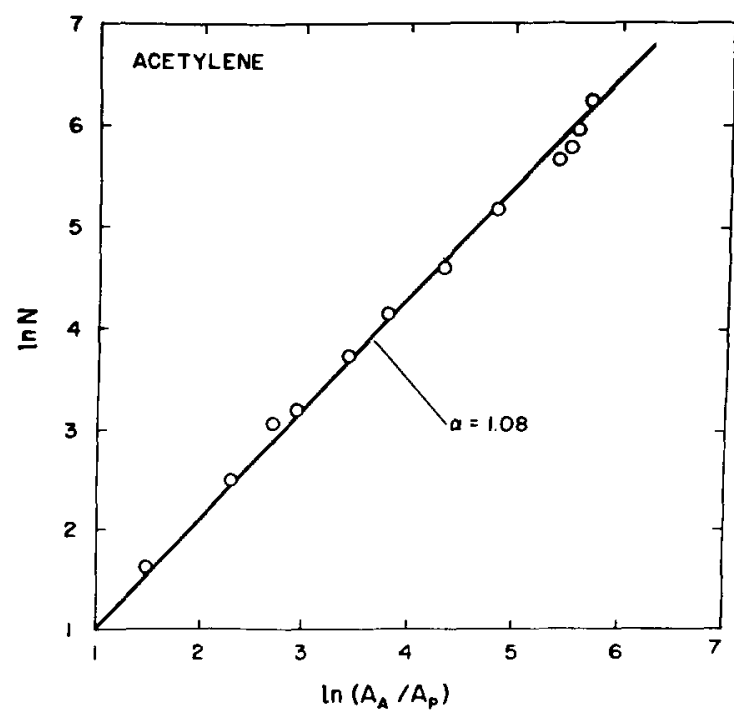

Fig. 3. Correlation between projected areas and number of primary particles for acetylene aggregates. tainty was $27 \%$. Typical probability density functions for $N$, along with the log-normal correlations of Eq. 1, are illustrated in Fig. 4. Results are shown for both acetylene and ethylene as before. The results, for $N$ in Fig. 4, exhibit greater scatter from the log-normal distribution than the results for $d_{p}$ in Fig. 2. There are two reasons for this behavior: the variance of $N$ is much greater than for $d_{p}$ and fewer numbers of aggregates than primary particles were sampled. From the information available, there is no reason to reject use of the log-normal distribution for $N$. However, the approximation of the $\operatorname{pdf}(N)$ as a normal distribution is not appropriate because mean values of $N$ generally are smaller than its standard deviation, $\sigma_{A}$, which implies large probabilities for unphysical negative values of $N$ using a normal distribution.

Results of the measurements of $N$ for all the fuels are summarized in Table 2. The relevant entries include the arithmetic and geometric mean values, $\bar{N}$ and $N_{g}$, and the corresponding standard deviations of these parameters, $\sigma_{A}$ and $\sigma_{A g}$. As noted earlier, the distributions of $N$ are unusually broad with $\bar{N}<\sigma_{A}$ and $N_{g}$ significantly lower than $\bar{N}$ for all the fuels. Noting that $\sigma_{A g}$ is of order unity, the results in Table 2 imply that roughly $95 \%$ of the aggregates have $N$ within a 50:1 range, that is, the range corresponding to two geometrical standard deviations. Thus, taking an average $N_{g}=226$ over all the fuels implies that $95 \%$ of the aggregates contain $30-1800$ pri-

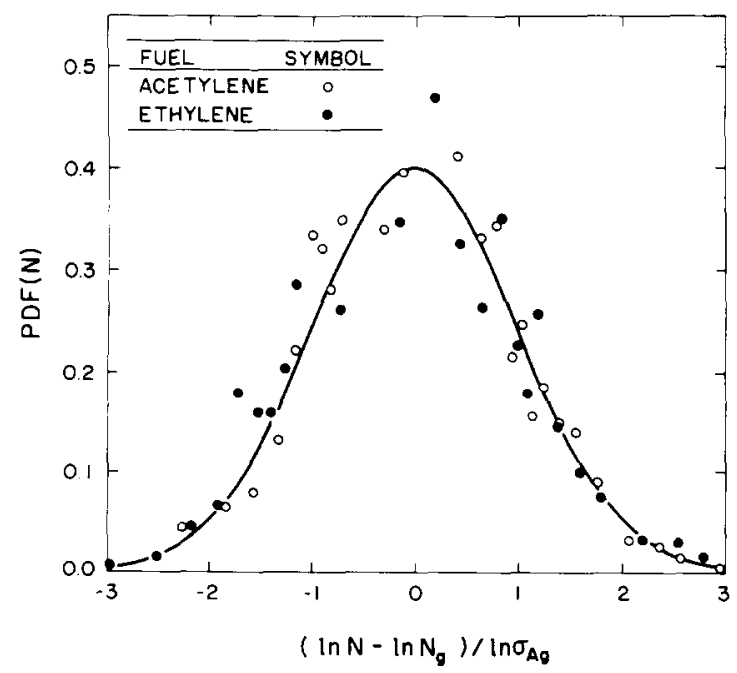

Fig. 4. Probability density functions of the number of primary particles per aggregate for acetylene and ethylene soot. 
mary particles. This means that the optical properties of aggregates are complex in the visible portion of the spectrum-ranging from Rayleigh scattering for small aggregates to significant effects of aggregate scattering for large aggregates, based on estimates from Refs. 4 and 5 .

Two parameters needed to estimate aggregate optical properties from Refs. 4 and 5, $D_{30}$ and $f_{n}$, are also summarized in Table 2. Following Ref. 9, both properties were estimated assuming that the primary particles were monodisperse spheres having diameters of $\bar{d}_{p}$, and that the primary particles make point contact. The volume mean diameter, $D_{30}$ is the diameter of a sphere having the same volume as the mean volume per aggregate; it is proportional to the absorption cross section of aggregates in the Rayleigh scattering regime [5]. Under the above assumptions, $D_{30}$ can be found as follows:

$D_{30}=\bar{N}^{1 / 3} d_{p}$

The values in Table 2 vary from 196 to $411 \mathrm{~nm}$, tending to increase with increasing tendency to soot. These values are comparable to optical wavelengths, which suggests potential for departure from Rayleigh scattering behaviorparticularly for the more heavily sooting fuels.

The scattering cross section of aggregates is related to the sixth moment of the volumetric size distribution, $D_{60}$; under present assumptions this parameter can be related to $D_{30}$ through the moment ratio $f_{n}$ as follows [9]:

$f_{n}=\left(D_{60} / D_{30}\right)^{6}=\bar{N}^{2} /(\bar{N})^{2}$.

Present values of $f_{n}$ are in the range 2.05-3.93, with experimental uncertainties ( $95 \%$ confidence) of $40 \%-90 \%$ in spite of the relatively large number of aggregates that were considered. These large uncertainties result because $f_{n}$ is related to squares of the number of particles per aggregate and the present aggregate size distributions are naturally broad: sampling unmanageably large numbers of aggregates would be required to reduce the uncertainties of $f_{n}$ to the same range as the other parameters in Table 2 . The ratio $f_{n}$ tends to increase with increasing tendency to soot. Present values are greater than those observed by Megaridis and Dobbins [9], ca. 1.8, in the underfire region of laminar ethylene/air flames for residence times approaching the smoke point residence time. The larger values of present measurements are reasonable, however, because of the much longer residence times available for aggregation in the present flames.

Soot aggregates generally exhibit mass fractallike behavior, yielding a relationship between $N$ and the radius of gyration of an aggregate, $R_{g}$, as follows $[6-9,11,12]$ :

$N=k_{f}\left(R_{g} / d_{p}\right)^{D_{f}}$,

where $k_{f}$ is the prefactor, $D_{f}$ is the Hausdorff or fractal dimension, and the assumption of monodisperse nonoverlapping primary particles has been invoked as before. Direct evaluation of $D_{f}$ from Eq. 7, however, requires extensive data reduction from stereopair images, which was not feasible due to the large range of conditions considered during the present investigation. Fortunately, Jullien and coworkers [11, 12] have shown that several projected aggregate dimensions can be used in expressions like Eq. 7 to yield essentially the same value of $D_{f}$. For present conditions, the best correlations were achieved using the geometric mean of the maximum projected length, $L$, and the maximum width normal to $L, W$, of the aggregates, as follows:

$N \sim\left((L W)^{1 / 2} / d_{p}\right)^{D_{f}}$

The mean value of $d_{p}$ was used to form the correlations according to Eq. 8 .

Example correlations to find $D_{f}$ from Eq. 8 are illustrated in Fig. 5. Results are illustrated for acetylene and ethylene (based on samples of roughly 310 aggregates for each fuel); however, the results for the other fuels were similar. The aggregates exhibit mass fractal behavior even when they contain only a few primary particles and general scaling as mass fractals is questionable. The slopes of these plots, based on leastsquares fits, yield $D_{f}$ through Eq. 8: the resulting values are summarized in Table 2 for all the fuels. The values of $D_{f}$ are in the range $1.70-1.79$, with experimental uncertainties $(95 \%$ confidence) less than 0.06, and do not exhibit any particular trend with respect to the sooting tendency of the fuel, that is, this variation is within the experimental uncertainties. Additionally, this 


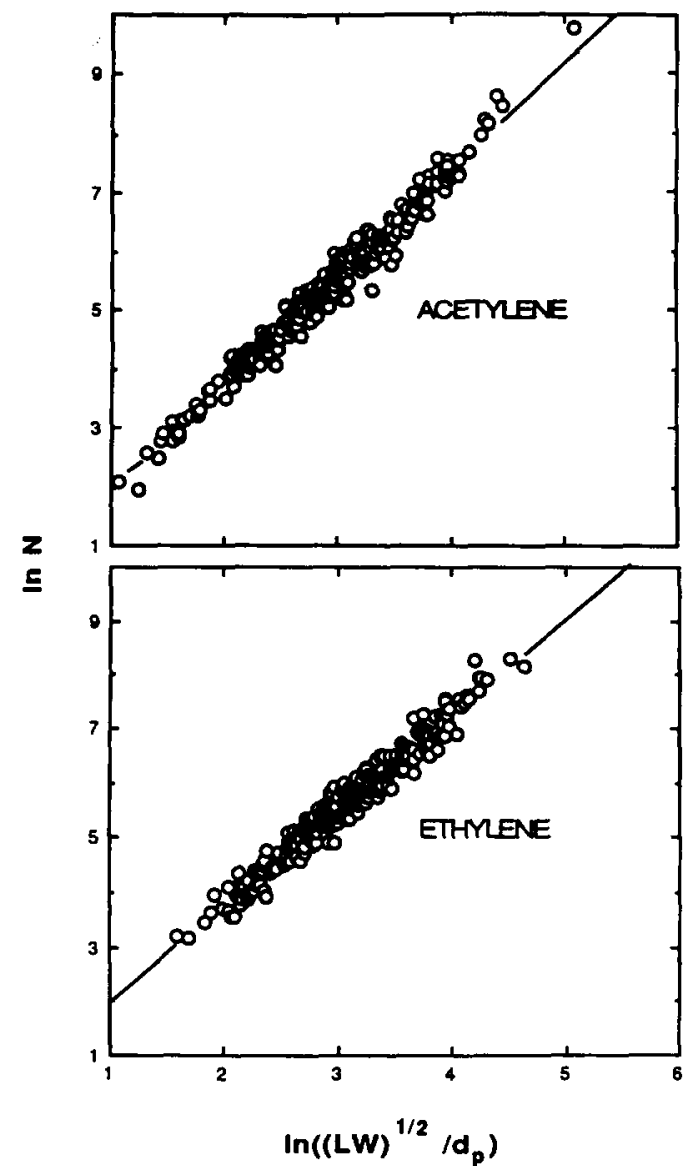

Fig. 5. Correlation between characteristic dimensions and number of primary particles yielding fractal dimensions of acetylene and ethylene aggregates.

range of values is typical of past determinations of $D_{f}$ for soot aggregates at shorter residence times; see Ref. 9 for a summary of earlier measurements. Thus, $D_{f}$ appears to be relatively universal for soot aggregates, with little variation with respect to fuel type, position in the overfire region, and residence time.

Given $D_{f}, R_{g}$ was evaluated from Eq. 7 in order to determine its mean value and standard deviation which are needed for estimates of aggregate optical properties [4, 5]. Two values of $k_{f}$ were considered during these computations: $k_{f}=5.8$, found from the simulated aggregates of Mountain and Mulholland [16], following Megaridis and Dobbins [9]; and $k_{f}=$ 9.4 (with a standard deviation of 1.9) found from the measurements of acetylene soot by Samson et al. [6], following Puri et al. [22]. In the follow- ing, results are presented for $k_{f}=5.8$, to correspond to Dobbins and Megaridis [4] treatment of soot aggregate optical properties; however, effects of using the higher value of $k_{f}$ will be noted. The computations involved averaging 160-320 aggregates for each fuel as before. The resulting values of mean and root-mean-squared radius of gyration, $\bar{R}_{g}$ and $\left(\bar{R}_{g}^{2}\right)^{1 / 2}$, are summarized in the last two columns of Table 2 for all the fuels. The values of $\bar{R}_{g}$ vary in the range 284-653 nm, with the larger values associated with the more heavily sooting fuels (use of the higher value of $k_{f}$ would yield values roughly $25 \%$ lower). The diameter of gyration is significantly larger than the volume mean diameter, for example, $2 \bar{R}_{g} / D_{30}$ is typically about 3 , which is representative of the open filmly structure of soot aggregates. Additionally, the standard deviation of $\bar{R}_{g}$ is generally larger than $\bar{R}_{g}$ itself, which is expected from Eq. 7 due to the broad range of $N$.

\section{Aggregate Structure Correlations}

The results of Table 2 are somewhat disappointing for two reasons: the aggregates are too large for proper use of the Rayleigh scattering approximation, so that their structure must be known to estimate their optical properties, and aggregate structure varies with fuel type even though effects of position in the overfire region and residence time were small in the long residence time regime. This implies that measurements of soot structure are needed to find the optical properties of each fuel. However, the variations of soot structure appear to be correlated with the sooting tendency of the fuels so that generalized correlations were sought as a means of circumventing the need to develop extensive information on the soot structure of every fuel.

Correlations of soot structure in terms of several fuel parameters were studied: $\mathrm{H} / \mathrm{C}$ ratio, laminar smoke point flame length, and laminar smoke point residence time. Of these, the laminar smoke point residence time yielded the best results, and these correlations are illustrated in Fig. 6. The soot structure parameters considered are $\bar{d}_{p}, N_{g}, f_{n}$, and $D_{f}$-other properties needed to estimate soot aggregate optical properties can be found from these parameters through Eqs. 5-7, recalling that $N_{g}$ and $f_{n}$ prescibe the first two moments of the $\operatorname{pdf}(N)$. 


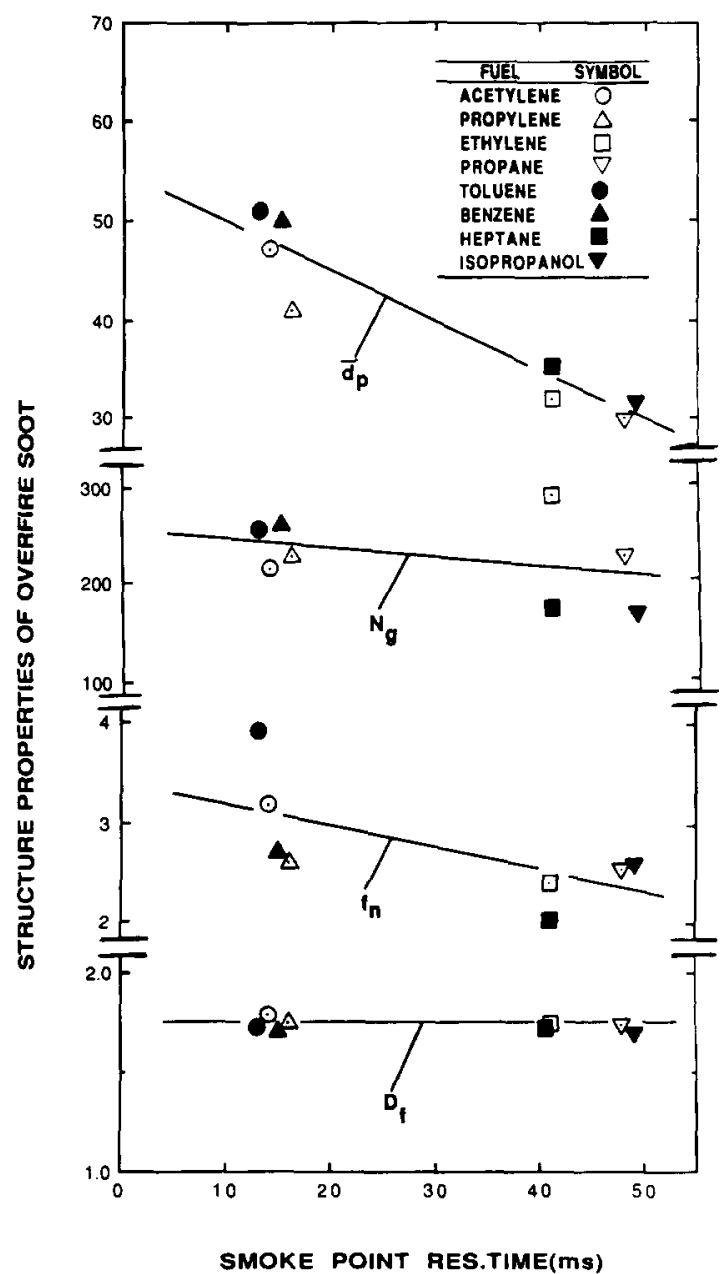

Fig. 6. Correlations between laminar smoke point residence times and aggregate structure parameters.

In general terms, the correlations illustrated in Fig. 6 exhibit a significant degree of scatter and are preliminary at best. The fractal dimensions did not vary significantly in comparison to experimental uncertainties, with $D_{f}=1.75$ having a standard error of estimate of 0.02 over the present test range. In contrast, $\bar{d}_{p}, N_{g}$, and $f_{n}$ decrease as $t_{s}$ increases, yielding the following linear fits over the present test range:

$d_{p}(\mathrm{~nm})=55-0.5 t_{s}$,

$N_{g}=255-t_{s}$,

$f_{n}=3.42-0.022 t_{s}$,

with $t_{s}$ (ms). For the present fuels, over the $t_{s}$ range of 13-49 $\mathrm{ms}$, the standard errors of esti- mate of Eqs. 9-11 for $d_{p}, N_{g}$, and $f_{n}$ are $3 \mathrm{~nm}$, 39 , and 0.44 , respectively. Although present correlations for $N_{g}, D_{f}, d_{p}$, and $f_{n}$ can help to provide estimates of conditions when overfire aggregate optical properties must be considered, more quantitative use will require consideration of additional fuels to better understand the limitations of the correlations.

\section{Generation Factors}

Assuming that soot structure was invariant in the overfire region for a particular fuel in the long residence time regime, present measurements were used in conjunction with earlier measurements of soot emissions $[1,3]$ to obtain information on the concentrations of primary particles and aggregates. The invariance of primary particle properties in the overfire region is assured because no changes are expected once oxidation reactions quench. Invariant aggregate properties, however, are more questionable because aggregation continues as the soot mixes passively in the overfire region [23]. Nevertheless, an evaluation discussed in the next section indicates that effects of aggregation are small in the overfire region for typical fire environments. This conclusion is also supported by the invariance of aggregate properties over the range of positions in the overfire region and residence times of the present tests.

Analogous to soot generation factors used to characterize soot emissions for long residence time flames $[1,3]$, primary particle and aggregate generation factors were used to characterize soot structure. These parameters are the number of primary particles or aggregates generated by the flame per kilogram of fuel carbon burned. They can be found from measurements of soot generation factors, as follows:

$$
\begin{aligned}
& \eta_{p}=6 \eta_{s} /\left(\pi \rho_{s} \bar{d}_{p}^{3}\right), \\
& \eta_{A}=\eta_{p} / \bar{N}
\end{aligned}
$$

Although soot density appears in Eq. 12, $\eta_{p}$ and $\eta_{A}$ actually are independent of $\rho_{s}$ because it simply cancels the soot density used to find $\eta_{s}$ from measurements of soot volume fractions. The soot volume fractions of Refs. 1 and 3 were obtained from laser extinction measurements at $632.8 \mathrm{~nm}$, using the refractive indices of Dalzell 
and Sarofim [24] at this wavelength (1.55$0.56 i$ ), and assuming that soot optical properties could be approximated by the small particle (Rayleigh) scattering approximation [1, 3], in order to be consistent with earlier work [25-27]. The refractive indices of Dalzell and Sarofim [24] have been questioned (see Refs. 1, 3, 28-30, and references therein); however, correcting present results to any new values appropriate for soot at present test conditions only involves a simple ratio. Similarly, consideration of aggregate optical properties, to be discussed later, indicates that use of the small particle limit requires correction as well, particularly for heavily sooting fuels. However, corrections of this type seem premature before current models of aggregate optical properties are experimentally assessed; if needed, they also only involve simple ratios of Rayleigh scattering estimates of soot volume fractions $[4,5]$. Finally, $\eta_{p}$ and $\eta_{A}$ are readily converted to other parameters, like primary particles or aggregates per unit volume, using state relationships under the approximations of the laminar flamelet concept because fuel carbon is proportional to mixture fraction $[1,3]$. These parameters are exploited subsequently to compare present findings with earlier measurements in laminar flames, and to assess effects of aggregation on the durability of the present soot structure measurements.

The values of $\eta_{S}$ from Refs. 1 and 3, as well as the values of $\eta_{p}$ and $\eta_{A}$ computed using Eqs. 12 and 13, are summarized in Table 3 for all the fuels. The values of $\eta_{s}$ in Table 3 are based on a soot density of $1100 \mathrm{~kg} / \mathrm{m}^{3}$ from Newman and Steciak [31] for consistency with earlier work $[1-3,25,26]$. The appropriate values of soot density are still not well established due to problems about soot optical properties, as discussed by Newman and Steciak [31]; however, as noted earlier, $\eta_{p}$ and $\eta_{A}$ are independent of soot density, so this difficulty is not a factor for present purposes. Values of $\eta_{p}$ vary in the range $1.7-$ $32 \times 10^{17}$ primary particles per kilogram of fuel carbon burned, generally tending to increase with increasing tendency to soot. However, $\eta_{p}$ varies less than $\eta_{s}$ over the range of fuels in Table 3 because much of the additional volume of soot is contained in the larger primary particles of the more heavily sooting fuels rather in additional numbers of primary particles. Values of $\eta_{A}$ in
TABLE 3

Generation Factors at Long Residence Times

\begin{tabular}{|c|c|c|c|}
\hline Fuel & $\begin{array}{c}\eta_{s}^{\alpha} \\
(\mathrm{kg} \text { soot } / \\
\mathrm{kg} \text { fuel } \mathrm{C})\end{array}$ & $\begin{array}{c}\eta_{p} \times 10^{-17} \\
\text { (primary particles/ } \\
\mathrm{kg} \text { fuel } \mathrm{C} \text { ) }\end{array}$ & $\begin{array}{c}\eta_{A} \times 10^{-14} \\
\text { (aggregates } \\
\mathrm{kg} \text { fuel } \mathrm{C} \text { ) }\end{array}$ \\
\hline Toluene & 0.16 & 21 & 40 \\
\hline Acetylene & 0.19 & 32 & 76 \\
\hline Benzene & 0.15 & 22 & 40 \\
\hline Propylene & 0.067 & 17 & 42 \\
\hline Ethylene & 0.018 & 9.5 & 20 \\
\hline$n$-Heptane & 0.010 & 4.0 & 16 \\
\hline Propane & 0.012 & 7.7 & 21 \\
\hline Isopropanol & 0.003 & 1.7 & 6.9 \\
\hline
\end{tabular}

${ }^{a}$ Long residence time soot generation factors from $\mathrm{Si}$ vathanu and Faeth [1] and Köylü and Faeth [3] based on a soot density of $1100 \mathrm{~kg} / \mathrm{m}^{3}$ from Ref. 31

Table 3 are in the range $6.9-76 \times 10^{14}$ aggregates per kilogram of fuel carbon burned, with trends with respect to sooting tendency similar to $\eta_{p}$; the latter behavior is expected from Eq. 13 because $\bar{N}$ does not vary greatly with fuel type.

The present concentrations of primary particles and aggregates can be compared with earlier measurements for laminar ethylene/air flames $[5,8]$ to gain an appreciation of differences between soot properties in long residence time turbulent flames and in laminar flames, by finding primary particle and aggregate concentrations per unit volume. Under the laminar flamelet approximations, the number of primary particles per unit volume in the overfire region can be found from

$$
n_{p}=\eta_{p} M_{C} f \rho / M_{F},
$$

where $\rho=\rho(f)$ is found from the state relationships for the flame, for example, like the generalized state relationships of Ref. 32. Evaluating Eq. 14 for ethylene at stoichiometric conditions ( $M_{C}$ and $M_{F}=24$ and $28 \mathrm{~kg} / \mathrm{kgmol}, f=0.064$, $\left.\rho=0.21 \mathrm{~kg} / \mathrm{m}^{3}\right)$, taken as an approximate bound for the overfire region that is representative of conditions in the flame, yields a primary particle density of roughly $10^{10}$ primary particles per cubic centimeter.

Megaridis and Dobbins [8] and Dobbins et al. [5] measured primary particle densities in the fuel-rich region of a laminar ethylene/air flame that was operating near the laminar smoke point residence time [27]. In both cases, measurements 
were confined to the region of maximum soot concentrations in the soot layer, although values of $f$, etc., were not reported. Megaridis and Dobbins [8] compute $n_{p}$ using the same procedure as present work and find values of $3-4 \times$ $10^{11}$ primary particles per cubic centimeter. Dobbins et al. [5] use the approximate theory of aggregate optical properties of [4] and find $n_{p}$ of $10^{12}$ primary particles per cubic centimeter. In both cases, $n_{p}$ at the maximum soot concentration condition did not vary appreciably with distance from the burner exit. Due to similarity of methods, present results are best compared with those of Ref. 8. Then, the roughly one-order of magnitude reduction of $n_{p}$ in the turbulent flames at stoichiometric conditions from values of maximum soot concentrations at fuel-rich conditions seems quite reasonable. First of all, soot in the overfire region involves contributions from all parts of the soot layer leaving the fuel-rich region, not only the portion having the maximum concentrations of soot. Additionally, fuel-rich conditions involve both larger densities and mixture fractions than stoichiometric conditions, which implies larger values of $n_{p}$ from Eq. 14. This finding suggests a relationship between soot properties in laminar and turbulent flames that is consistent with other comparisons of soot properties between laminar and turbulent flames [33-35]. However, additional measurements of the properties of soot emissions in laminar flames are needed to evaluate this idea more definitely.

\section{Aggregation}

Based on present measurements, $\eta_{p}$ is constant for a particular fuel at long residence times and is not expected to change within the overfire region. Additional aggregation, however, can be expected even though $\eta_{A}$ did not vary over the present test range for a particular fuel. Thus, the degree of aggregation in the overfire region is an important issue that affects corresponding variations of soot optical properties. This involves potential changes in $\bar{N}$ from stoichiometric conditions to the relatively low values of $f$ where present measurements were made, as well as potential subsequent variations at larger distances from the flame within the fire plume.

Aggregation in the overfire region was considered following the simplified arguments of
[5, 36], as well as the more detailed considerations of Baum and Mulholland [23] for aggregation in plumes. Following $[5,36]$, the fractional rate of aggregation can be expressed as follows:

$$
\left(d n_{A} / d t\right) / n_{A}=-K n_{A} .
$$

Within the overfire region, $n_{A}$ is maximum at the stoichiometric condition, having values of roughly $2 \times 10^{7}$ aggregates per cubic centimeter based on $n_{p}$ of $10^{10}$ primary particles per cubic centimeter at these conditions found earlier and an average value of $\bar{N}$ of 400 particles per aggregate for the fuels listed in Table 3. Then choosing typical values of $K$ in the range $10^{-9}-10^{-8} \mathrm{~cm}^{3} / \mathrm{s}$ from Ref. 36, the rate of change of $n_{A}$ at stoichiometric conditions is $2 \%-20 \% \mathrm{~s}^{-1}$, which is relatively small for residence times of interest in the overfire region (ca. $100 \mathrm{~ms}$ ). Through Eq. 13, the rate of change of $N_{A}$ decreases to $0.2 \%-2 \%$ $\mathrm{s}^{-1}$ at conditions of the present measurements $(f$ of roughly $10^{-3}$ ), and even more rapidly thereafter because $f$ continues to decrease while $\rho$ remains relatively constant. Thus, it appears that rates of aggregation are small in the overfire region so that the state of the aggregates is frozen beyond the point where oxidation reactions quench, for long residence time flames. Similar conclusions are reached using the more elegant considerations of Baum and Mulholland [23]. Additionally, this behavior is certainly consistent with the negligible variation of $\bar{N}$ observed for various positions and residence times during present experiments. Thus, the degree of aggregation of soot in the overfire region of unconfined overventilated flames at long residence times appears to be invariant for practical purposes, like other properties of soot structure. Naturally, this observation may not be pertinent to confined flames, which can involve long residence times at high soot concentrations within ceiling layers.

\section{Aggregate Optical Properties}

The final issue to be discussed in conjunction with present measurements of soot structure is the optical properties of soot aggregates. For lack of an alternative analytical method, these considerations are based on the approximate theory of soot aggregate optical properties of Dobbins and Megaridis [4]. However, a number of question- 
able approximations about aggregate optical properties are involved in the development of this approach so that the results are only preliminary pending experimental evaluation of the method.

The main difficulties of the approach of Ref. 4 are that the results of Mountain and Mulholland [16] are used to correlate basic features of the aggregate optical model. These calculations are based on the assumptions of Rayleigh-GansDebye or Born approximation and effects of multiple scattering are ignored. Conditions for use of the Rayleigh-Gans-Debye limit are that $\mid m-$ $1 \mid \ll 1$ and $2 \alpha_{p}|m-1| \ll 1$. Using typical values for the indices of refraction of soot $[5,24$, 28-30], however, yields $|m-1|$ of order unity, which is not consistent with Rayleigh-GansDebye scattering. Additionally, present measurements of $d_{p}$ indicate that $2 \alpha_{p}|m-1|$ is in range $0.1-0.3$ at a wavelength of $632.8 \mathrm{~nm}$, which is of interest for evaluating past measurements of soot volume fractions in flames: these conditions also are marginal for application of Rayleigh-Gans-Debye theory. With respect to the effects of multiple scattering for aggregates of small primary particles, Berry and Percival [17] argue that effects of multiple scattering for $D_{f}<2$ are negligible everywhere when

$N \ll \alpha_{p}^{-D_{f}}$

or if $N \gg \alpha_{p}^{-D_{f}}$, when

$\alpha_{p} \ll\left[\frac{\left|m^{2}-1\right| 2^{1-D_{f}}\left(D_{f}\left(D_{f}+1\right)\right)^{D_{f} / 2}}{3\left(D_{f}-1\right)\left(2-D_{f}\right)}\right]^{1 /\left(D_{f}-3\right)}$.

It is the second condition that provides the limitation for overfire soot, requiring that $\alpha_{p} \ll 0.15$, which is never satisfied for present aggregates in the visible and near-infrared portions of the spectrum. Additionally, the computations of Nelson [18], for simulated soot aggregates, directly show the importance of multiple scattering for large aggregates typical of those observed during the present investigation. Thus, it appears that more complete treatment of aggregate scattering requires consideration of effects of multiple scattering, other approximations of Ref. 4 aside.

In spite of the difficulties of the approximate theory of aggregate optical properties, it is still of interest to consider the results as an indication of potential departure of aggregate scattering properties from the small particle (Rayleigh) scattering limit. This is represented conveniently by the mean ratio of the scattering-to-absorption cross sections of the aggregates, $\bar{\rho}_{s a}$ as follows [4]:

$$
\begin{aligned}
\bar{\rho}_{s a}= & \frac{f_{V R}}{f_{V A}}-1 \\
= & \frac{2}{3} \frac{F(m)}{E(m)} \alpha_{p}^{3} \bar{N} f_{n} \\
& \times\left[1+\frac{16}{3 D_{f}}\left(\frac{\alpha_{p}}{d_{p}}\right)^{2} \bar{R}_{g}^{2}\right]^{-D_{f} / 2},
\end{aligned}
$$

where

$$
E(m)=-\operatorname{Im}\left(\frac{m^{2}-1}{m^{2}+2}\right), F(m)=\left|\frac{m^{2}-1}{m^{2}+2}\right|^{2}
$$

and $m$ is the complex index of refraction of soot. A useful bound for $\bar{\rho}_{s a}$ for large aggregates can be found, assuming that $\bar{R}_{g}^{2}$ and $\bar{N}$ can be related by Eq. 7, or more precisely stated that the aggregates are large and monodisperse, as follows [4]:

$\bar{\rho}_{S a}=\frac{2}{3} \frac{F(m)}{E(m)} \alpha_{p}^{3} k_{f}\left(3 D_{f} /\left(16 \alpha_{p}^{2}\right)\right)^{D_{f} / 2}$.

The results of Eq. 20 suggest that effects of aggregate size on $\bar{\rho}_{s a}$ disappear as $\bar{N}$ becomes large, that is, aggregate scattering properties saturate for large aggregates. The calculations of Nelson [18], allowing for multiple scattering, also exhibit saturation for scattering for large aggregates. This behavior is markedly different from closely packed aggregates approximated by spherical particles using Mie-scattering theory where $\bar{\rho}_{s a}$ varies continuously as $\bar{N}$ increases [4].

Using the soot structure properties of Table 2, in conjunction with Eq. $18, \bar{\rho}_{s a}$ was found as a function of wavelength in the visible and nearinfrared portions of the spectrum. These results are plotted in Fig. 7 for all the fuels based on $k_{f}=5.8$. The results are presented as $\bar{\rho}_{s a} E(m) / F(m)$ to avoid complications of the considerable uncertainties of proper soot refractive indices. The departure from the Rayleigh 


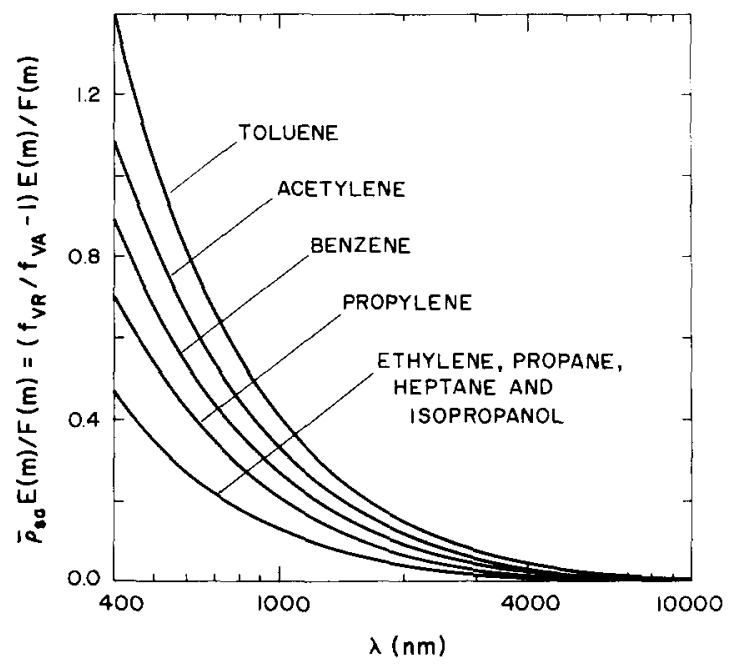

Fig. 7. Mean ratios of scattering to absorption cross sections as a function of wavelength for polydisperse aggregates.

scattering limit, $\bar{\rho}_{s a} \approx 0$, is largely governed by $d_{p}$, with $\bar{N}$ and $\bar{R}_{g}^{2}$ being secondary factors. Thus, the magnitude of the departure is greatest for the strongly sooting materials. Additionally, $\bar{\rho}_{s a}$ decreases with increasing wavelength, reaching small values for all soot observed during the present investigation at wavelengths on the order of $10^{4} \mathrm{~nm}$.

Effects of aggregate scattering can be viewed in a different way from Fig. 8. This involves plots of $\bar{\rho}_{s a}$ as a function of $\bar{N}$, assuming that Eq. 7 can be used to relate $\bar{R}_{g}^{2}$ and $\bar{N}$ in Eq. 18 , and that $f_{n}$ for each fuel remains constant as $\bar{N}$ varies. Results are illustrated at two different wavelengths (note the different scales of the ordinates of the two plots): $632.8 \mathrm{~nm}$, which is representative of the wavelengths used to find soot volume fractions from laser extinction measurements, and $2000 \mathrm{~nm}$, which is representative of wavelengths where radiant emission from flames is largest. These results have been computed for $k_{f}=5.8$ from Dobbins and Megaridis [4]; use of $k_{f}=9.4$ from Samson et al. [6] would increase the saturated $\bar{\rho}_{s a}$ at large $\bar{N}$ by roughly $60 \%$. The plots have been constructed for all the fuels, with the data symbols on each indicating the behavior of the present soot aggregates.

Results illustrated in Fig. 8 show the transition from nearly Rayleigh scattering behavior for small aggregates to saturated aggregate scattering for

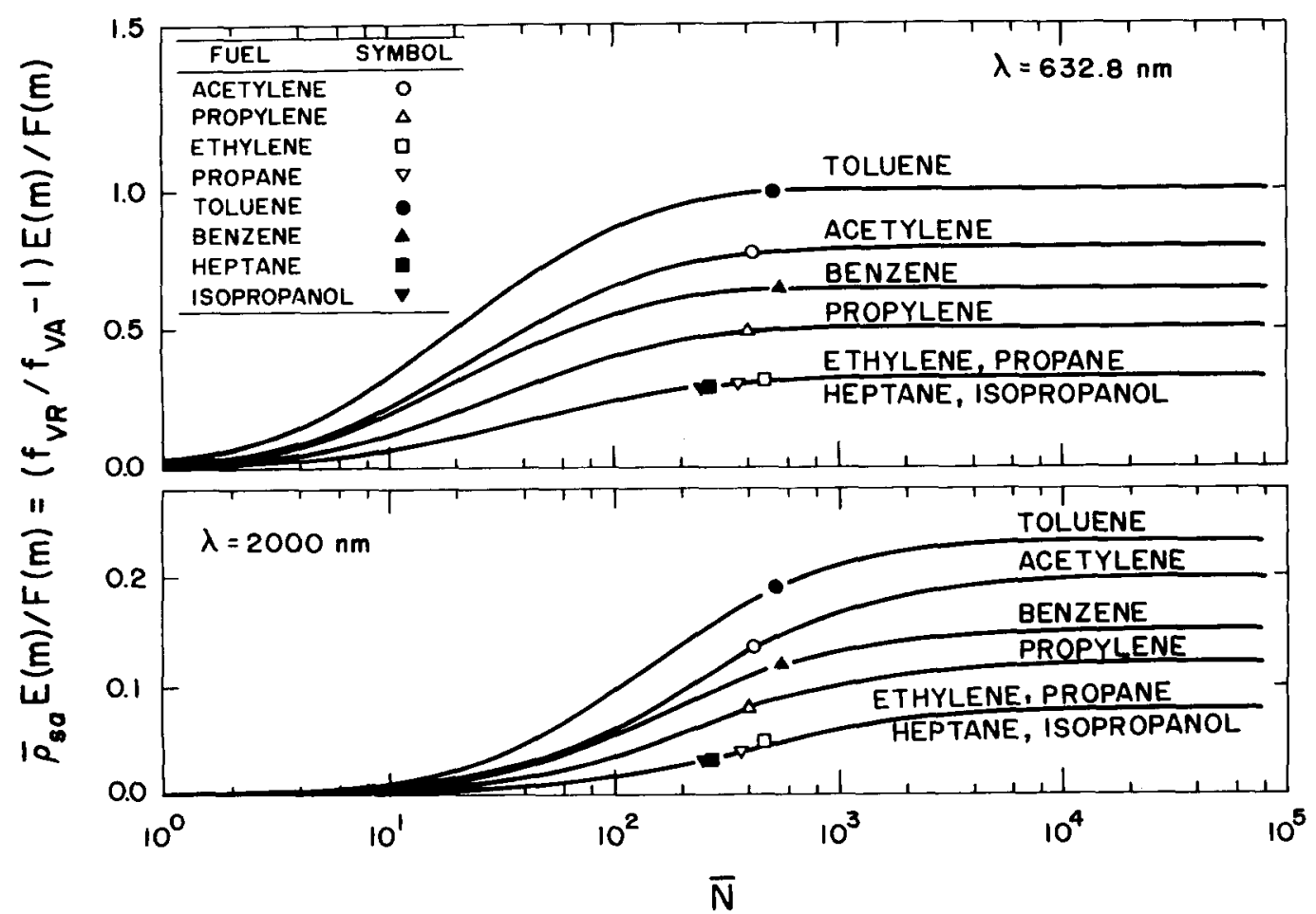

Fig. 8. Mean ratios of scattering to absorption crossections as a function of mean aggregate size for polydisperse aggregates. 
larger aggregates. The present aggregates approach saturated aggregate scattering at $632.8 \mathrm{~nm}$, and are intermediate between Rayleigh and saturated aggregate scattering at $2000 \mathrm{~nm}$. The additional scattering from aggregates causes soot volume fractions to be overestimated by laser extinction measurements analyzed using the Rayleigh scattering approximation. Noting that $F(m) / E(m)$ is of order unity [4], such measurements at $632.8 \mathrm{~nm}$ overestimate soot volume fractions by nearly a factor of two for a heavily sooting material like toluene and by roughly $30 \%$ for lightly sooting materials like ethylene, $n$-heptane, propane, and isopropane. However, the uncertainties of the approximate aggregate scattering theory, discussed earlier, particularly as saturated conditions are approached, should be kept in mind when interpreting this result. In particular, effects of the larger $k_{f}$ and consideration of secondary scattering would both act to increase $\bar{\rho}_{s a}$ from the results illustrated in Fig. 8 . Additionally, current estimates of the refractive index function of soot, $F(m) / E(m)$, also vary by roughly a factor of $2(0.8-1.7)$ [4] and in some cases involve errors due to unknown aggregate scattering effects [28].

The results in Fig. 8 at $632.8 \mathrm{~nm}$ suggest significant effects of fuel type on the optical properties of soot when measurements of soot volume fractions are made in the visible portion of the spectrum. On the other hand, Mulholland et al. [37] and Newman and Steciak [31] conclude that soot from various fuels, ranging from lightly to heavily sooting materials, have essentially the same specific extinction coefficient. Review of the Mulholland et al. [37] data, however, reveals variations of specific extinction coefficients that are comparable to the range illustrated in Fig. 8 (although the correlation with sooting propensity is less evident). Additionally, the Newman and Steciak [31] measurements all involve use of Mie scattering theory, which raises questions about their conclusions concerning effects of fuel type because this approach is not very effective for treating aggregate scattering properties [18].

Clearly, there currently are weaknesses in both theoretical and experimental assessments of soot aggregate optical properties. Thus, more must be known about the optical properties of soot aggregates before more than order of magnitude accuracy can be attributed to laser extinction measurements of soot volume factions using the visible portion of the spectrum. Conversely, effects of aggregate scattering at $2000 \mathrm{~nm}$ are generally less than $20 \%$ over the present range of fuels, which is small in comparison with uncertainties about soot refractive indices; therefore, neglect of scattering when finding the radiative properties of soot still seems reasonable in comparison to other uncertainties of such computations; see Refs. 33 and 34 and references therein.

\section{CONCLUSIONS}

The structure of soot was studied for the fuel-lean (overfire) region of unconfined overventilated buoyant turbulent diffusion flames burning in still air within the long residence time regime. The following fuels were considered: toluene, acetylene, benzene, propylene, ethylene, $n$-heptane, propane, and isopropanol. The main conclusions of the study are as follows:

1. The physical properties of soot vary with fuel type but are relatively independent of position in the overfire region and flame residence time. Additionally, aggregation rates are small in the overfire region, due to relatively low aggregate concentrations, so that aggregate statistics are essentially constant from the stoichiometric condition throughout the region of the plume of interest for practical fires.

2. Primary particle diameters satisfied log-normal pdfs (nearly Gaussian pdfs) having mean diameters of $30-51 \mathrm{~nm}$ and standard deviations of 6-9 $\mathrm{nm}$. The larger primary particles were associated with more heavily sooting fuels in a manner that could be roughly correlated in terms of the laminar smoke point residence time (Fig. 6).

3. The number of primary particles per aggregate satisfied log-normal pdfs. The geometric mean number of particles per aggregate was relatively constant over all the fuels, having a mean value and standard deviation from this mean of 226 and 42 particles per aggregate. The range of these distributions was quite broad, however, with $95 \%$ of the aggregates having between 30 and 1800 primary particles per aggregate. Aggregate fractal or Hausdorff dimensions were relatively independent of the fuel type, varying in the range 1.70-1.79. Aggregate properties could be correlated roughly in terms of the laminar 
smoke point residence time, as illustrated in Fig. 6.

4. In conjunction with existing approximate theories of soot aggregate optical properties [4, 5], present observations suggest significant effects of aggregate scattering in the visible range of the spectrum, with extinction cross sections a factor of 2 higher than estimates based on the Rayleigh scattering approximation for a heavily sooting fuel like toluene. Additionally, the present structure measurements suggest significant effects of multiple scattering for all the fuels, which is ignored in current existing approximate theories of soot aggregate optical properties based on Dobbins and coworkers $[4,5]$. Thus, past observations of soot emissions at long residence times $[1-3,25,26]$, and theories of aggregate optical properties $[4,5]$, should be reconsidered in view of present soot structure observations.

This research was supported by the Building and Fire Research Laboratory of the National Institute of Standards and Technology, Grant No. 60NANB8D033, with H. R. Baum serving as Scientific Officer.

\section{REFERENCES}

1. Sivathanu, Y. R., and Faeth, G. M., Combust. Flame 81:133-149 (1990).

2. Köylï, Ü. Ö., Sivathanu, Y. R., and Faeth, G. M., Fire Safety Science: Proceedings of the Third International Symposium, Elsevier, London, 1991, p. 625.

3. Köylü, ̈̈. Ö., and Faeth, G. M., Combust. Flame 87:61-76 (1991).

4. Dobbins, R. A., and Megaridis, C. M., Appl. Optics 30:4747-4754 (1991).

5. Dobbins, R. A., Santoro, R. J., and Semerjian, H. G., Twenty-Third Symposium (International) on Combustion, The Combustion Institute, Pittsburgh, 1990, p. 1525.

6. Samson, R. J., Mulholland, G. W., and Gentry, J. W., Langmuir 3:272-281 (1987).

7. Dobbins, R. A., and Megaridis, C. M., Langmuir 3:254-259 (1987).

8. Megaridis, C. M., and Dobbins, R. A., Combust. Sci. Technol. 66: 1- 16 (1989).

9. Megaridis, C. M., and Dobbins, R. A., Combust. Sci. Technol. 71:95-109 (1990).

10. Medalia, A. I., and Heckman, F. A., Carbon 7:567582 (1969).

11. Tence, M., Chevalier, J. P., and Jullien, R., J. Phys. (Paris) 47:1989-1998 (1986).

12. Botet, R., and Jullien, R., Aggregation and Fractal
Aggregates, World Scientific Publishing, Singapore, 1987.

13. Jones, A. R., Proc. R. Soc. A 366:111-127 (1979).

14. Felske, J. D., Hsu, P.-F., and Ku, J. C., J. Quant. Spectrosc. Radiat. Transf. 35:447-465 (1986).

15. Kumar, S., and Tien, C. L., Combust. Sci. Technol. 66:199-216 (1989).

16. Mountain, R. D., and Mulholland, G. W., Langmuir 4:1321-1326 (1988).

17. Berry, M. V., and Percival, I. C., Opt. Acta 33:577-591 (1986).

18. Nelson, J., J. Mod. Opt. 36:1031-1057 (1989).

19. Bohren, C. F., and Huffman, D. R., Absorption and Scattering of Light by Small Particles, Wiley, New York, 1983.

20. Eisner, A. D., and Rosner, D. E., Combust. Flame 61:153-166 (1985).

21. Hinds, W. C., Aerosol Technology, Wiley, New York, 1982, p. 83, 154.

22. Puri, R., Richardson, T. F., Santoro, R. J., and Dobbins, R. A., personal communication, 1991.

23. Baum, H. R., and Mulholland, G. W., J. Colloid Interface Sci. 72:1-12 (1979).

24. Dalzell, W. H., and Sarofim, A. F., J. Heat Transf. 91:100-104 (1969).

25. Tewarson, A., in SFPE Handbook on Fire Protection Engineering, National Fire Protection Association, Quincy, MA, 1988, pp. 1-179.

26. Tewarson, A., and Newman, J. S., Fire Safety Science: Proceedings of the First International Symposium, Hemisphere, Washington, 1986, p. 451.

27. Santoro, R. J., Semerjian, H. G., and Dobbins, R. A., Combust. Flame 51:203-218 (1983).

28. Tien, C. L., and Lee, S. C., Prog. Ener. Combust. Sci. 8:41-59 (1982).

29. Habib, Z. G., and Vervisch, P., Comb. Sci. Technol. 59:261-274 (1988).

30. Charalampopoulos, T. T., Chang, H., and Stag, B., Fuel 68:1173-1179 (1989).

31. Newman, J. S., and Steciak, J., Combust. Flame 67:55-64 (1987).

32. Sivathanu, Y. R., and Faeth, G. M., Combust. Flame 82:211-230 (1990).

33. Gore, J. P., and Faeth, G. M., Twenty-First Symposium (International) on Combustion, The Combustion Institute, Pittsburgh, 1986, p. 1115.

34. Gore, J. P., and Faeth, G. M., J. Heat Transf. 110:173-181 (1988).

35. Sivathanu, Y. R., and Faeth, G. M., Combust. Flame 81:150-165 (1990).

36. Megaridis, C. M., and Dobbins, R. A., Twenty-Second Symposium (International) on Combustion, The Combustion Institute, Pittsburgh, 1988, p. 353.

37. Mulholland, G. W., Henzel, V., and Babrauskas, V., Fire Safety Science: Proceedings of the Second International Symposium, Hemisphere, Washington, 1988, p. 347 .

Received I August 1991; revised 14 January 1992 